\title{
The Clinical Usefulness of Preoperative Imaging Studies to Select Pathologic Level in Cervical Spondylotic Myelopathy: Comparative Analysis of Three-Position MRI and Post-Myelographic CT
}

\author{
Seung Yoon LEE, Jung-Woo HUR, Kyeong-Sik RYU, Jin-Sung KIM, Ho-Jung CHUNG, Myung-Soo SONG \\ The Catholic University of Korea, College of Medicine, Seoul St. Mary's Hospital, Department of Neurosurgery, Seoul, Korea
}

\section{ABSTRACT}

\begin{abstract}
AIM: To compare the accuracy of determining pathologic segment between three-position MRI (3P-MRI) and post-myelographic CT (PMCT) in cervical spondylotic myelopathy (CSM) by assessing the degree of inter-observer and intra-observer agreement.

MATERIAL and METHODS: We retrospectively reviewed 3P-MRI and PMCT for the diagnosis of multilevel CSM in 136 patients who underwent surgery. Using an assessment scale, 8 blind observers with various clinical experiences examined 5 parameters: spinal canal narrowing, foraminal stenosis, bony abnormality, intervertebral disc herniation, and nerve root compression. Spinal canal, neural foraminal, spinal cord and disc protrusion diameters were measured. Intra-observer and inter-observer agreement of each image was analyzed.
\end{abstract}

RESULTS: Spinal canal width and foraminal diameter was found to be significantly smaller in 3P-MRI compared to PMCT. No significant differences of cervical cord diameter and the size of disc protrusion measured in 3P-MRI compared to PMCT were observed. Comparing between 3P-MRI and PMCT, disc abnormality and nerve root compression showed better agreement on 3P-MRI, whereas foraminal stenosis and bony lesion showed better agreement on PMCT.

CONCLUSION: In the present study, PMCT was still useful in diagnosis of the foraminal stenosis and bony lesion compared to 3P-MRI but showed limitation in disc abnormality and nerve root compression. Even though PMCT may provide valuable additional information in difficult or ambiguous cases, universal standard of 3P-MRI showed higher reliability in detecting pathologic levels in CSM patients.

KEYWORDS: Cervical spondylotic myelopathy, Dynamic magnetic resonance imaging, Post-myelographic computer tomography, Inter-observer agreement, Intra-observer agreement

\section{INTRODUCTION}

$\sim$ ervical spondylotic myelopathy (CSM) is a troublesome disease with diverse pathology and symptoms. Often it is difficult to confirm the main pathology leading to symptoms, especially in multi-level disease, and accurate diagnosis is important for deciding on the optimal treatment modality. With the advancement of imaging modalities, the surgical outcome and neurologic recovery have improved dramatically $(23,29)$. However, assessment of exact pathologic segment in multi-level CSM is still demanding.

Magnetic resonance imaging (MRI) is usually accepted as the primary and best diagnostic tool to evaluate $\operatorname{CSM}(2,10)$. It is possible to diagnose neural compression by canal and differentiate an intramedullary lesion simultaneously with a 
single scan. Before the era of MRI, post-myelographic CT (PMCT) was considered as the gold standard for complex spinal pathologies $(11,21)$. Compared to MRI, use of PMCT has diminished, due to unnecessary invasiveness and complications of the technique, and is usually reserved for ambiguous MRI results or technically suboptimal results $(15,18,21)$. Many studies comparing MRI and PMCT for CSM have yielded diverse results $(14,25,30)$.

After the recent introduction and validation of its usefulness $(13,16,20,27)$, dynamic (flexion-extension or kinematic) MRI has gained in popularity worldwide. The pathophysiology of CSM is the result of synergic action of both static and dynamic factors and the dynamic factor and related volume change is important for the flexibility of the cervical spine in CSM. Recent studies showed the superiority of dynamic MRI in some complex CSM patients but the results are still controversial $(2,6,10,17)$. PMCT and dynamic MRI are two choices available to surgeons when the conventional MRI results are suboptimal or controversial. However, there is no study comparing these two meaningful second line imaging modalities in CSM patients.

The objective of this study was to compare the accuracy of determining the pathologic segment between three-position MRI (3P-MRI; neutral, flexion \& extension) and PMCT in CSM by assessing the degree of inter-observer and intra-observer agreement.

\section{- MATERIAL and METHODS}

\section{Patient Selection}

Since 2009, we have performed routine 3P-MRI and PMCT for all newly diagnosed CSM patients in our institute. Our hypothesis was that using 3P-MRI with the aid of PMCT, the exact levels of pathology could be confirmed without missing any. We retrospectively reviewed 3P-MRI and PMCT for the diagnosis of multi-level CSM in 136 patients who underwent surgery from June 2009 to August 2016 (86 months).

\section{Data Collection}

Routine 3P-MRI examination was performed in all study subjects (3T Magnetom, SIEMENS, Erlangen, Germany). After routine MRI was obtained in the neutral position, flexionextension MRI was performed carefully with the help of custombuilt positioning sponge under the head and shoulders and at least one medical doctor attending for close observation. Due to economic issues, only T2W sagittal and axial images ( $3 \mathrm{~mm}$ continuous slice without skip interval) were achieved in 3P-MRI. Routine PMCT examination was performed using the technique by Kretzschmar (11). Lumbar puncture at the L5-S1 level was performed with 20 gauge spinal tapping needle and $20 \mathrm{ml}$ of iohexol was injected at a slow rate by a medical doctor. PMCT was performed within 1 hours of infiltration with $3 \mathrm{~mm}$ thickness sections in the disc space and $5 \mathrm{~mm}$ thickness in the vertebral body. Additional sagittal, coronal and 3D-image reconstruction was done in all study subjects. To monitor the possible adverse events after intrathecal injection of contrast agents, all patients were closely monitored at the day care unit with intravenous hydration for at least 2 hours.
Using a Likert-type assessment scale (26), 8 blind observers specialized in spine surgery with various clinical experiences examined 5 parameters: spinal canal narrowing, foraminal stenosis, bony abnormality, intervertebral disc herniation, and nerve root compression (Table I). The degree of severity was graded using a 4-point scale for each item. Foraminal stenosis and nerve root compression was difficult to differentiate due to overlapping of pathology. Therefore, we defined foraminal stenosis as only stenosis itself caused by bony spur or disc lesion. Nerve root compression was defined as direct compression or displacement of nerve root on MRI and subarachnoid space occlusion or filling defect in foramen on PMCT. Another controversy was about the determination of disc herniation by each surgeon. Disc herniation was confirmed only if 1) direct demonstration of disc material protruding past vertebral body margin was seen either on the sagittal or axial image on MRI images, or 2) attenuating soft disc material herniated beyond the vertebral margin and indentation of the thecal sac or cervical cord by soft tissue disc material was present on PMCT images.

Both MRI and PMCT was presented independently and blindly 3 times to each observer without any previous information about the patient information or clinical data using digitalized radiographic images displayed at the PACS (Picture Archiving and Communication System) terminal (Marosis 2003, Seoul, Korea). There was at least 1 week interval between each analysis. Spinal canal, neural foraminal, spinal cord and disc protrusion diameters were measured in the axial plane of MRI and PMCT on the digital radiographic image displayed by the PACS terminal by observers at each analysis (Figure 1). Routine C3 to C7 level axial images of all study subjects (5 levels each, total 680 segments) was presented to each observer for measurement. Each diameter was measured according to specific criteria; 1) spinal canal diameter was measured at the level of the disc space in the midline from the dorsal part of the annulus to the ventral part of the lamina, 2) foraminal diameter at the midline part of the foramen between the bony borders at each segment, 3) spinal cord diameter at the level of the disc space in the midline, and 4) disc protrusion diameter at the anterior-posterior dimension at the most pronounced site. For the 3P-MRI, mean value of three different positions were measured. Two additional questions were asked to each observer at time of analysis; 1 ) "what is the level of pathology" and 2) "which segments require operation".

\section{Statistical Analysis}

Intra-observer and inter-observer agreement of each image was analyzed. Statistical parameter of intra-class correlation coefficient (ICC) values of 3 scores in each observer was calculated for valuation of intra-observer correlation and reliability. Statistical parameter of inter-class correlation coefficient (ICC) values of 3 scores in each observer was calculated for valuation of inter-observer correlation \& reliability. ICC value (Cronbach's a) was analyzed by standardized confidence analysis and categorized as following; poor (a $<0.4$ ), fair to good ( 0.4 to 0.7 ), excellent $(a>0.7)$. Mean values of diameters measured and their standard deviations were calculated and paired $t$ tests performed for statistical analysis. 
Statistical differences with an error probability of $p$ value less than 0.05 was accepted as significant. All statistical analysis was done using SPSS version 12.0.

\section{RESULTS}

Results of inter-observer and intra-observer agreement are shown in Table II. There was a moderate correlation in both intra-observer (0.63), and inter-observer (0.52) correlation with higher intra-observer correlation values. Furthermore, there was no significant difference in intra-observer and inter-observer agreement between 3P-MRI and PMCT. Mean correlation values for $3 \mathrm{P}-\mathrm{MRI}$ was 0.58 (intra-observer 0.63 , inter-observer 0.53 respectively) and mean correlation value for PMCT was 0.56 (intra-observer 0.58, inter-observer 0.55 respectively). Comparing 3P-MRI and PMCT, disc abnormality and nerve root compression showed better agreement on 3P-MRI, whereas foraminal stenosis and bony lesion showed better agreement on PMCT. However, there was no statistical difference in intra-observer and inter-observer agreement between 3P-MRI and PMCT for spinal canal stenosis.

Results of mean values for measured diameters and the discrepancies between 3P-MRI and PMCT are shown in Table III. Measured spinal canal width was significantly narrower in 3-MRI than PMCT. Mean spinal canal diameter discrepancy between 3P-MRI and PMCT was about $10 \%$, consisting of $8.7 \%$ in non-stenosed and $14.3 \%$ in stenosed segments (Figure 2A). Foraminal diameter was found to be significantly smaller in 3P-MRI compared to PMCT with mean discrepancy

Table I: Five Different Parameters were Assessed Using Likert-Type Grading Scales: Spinal Canal Narrowing, Foraminal Stenosis, Bony Abnormality, Intervertebral Disc Herniation, and Nerve Root Compression

\begin{tabular}{|c|c|c|c|c|}
\hline \multirow{2}{*}{ Parameters } & \multicolumn{4}{|c|}{ Grade } \\
\hline & 0 (normal) & 1 (minimal) & 2 (moderate) & 3 (severe) \\
\hline $\begin{array}{l}\text { Spinal canal } \\
\text { stenosis }\end{array}$ & Normal & $\begin{array}{l}\text { Disc touches but does } \\
\text { not deform cord }\end{array}$ & $\begin{array}{l}<50 \% \text { indentation of } \\
\text { cord, possible mild } \\
\text { flattening }\end{array}$ & $\begin{array}{l}\text { Cord displacement }>50 \% \\
\text { flattening }\end{array}$ \\
\hline Foraminal stenosis & Normal & Minor encroachment & Definite encroachment & $\begin{array}{c}\text { Narrowing of foramen } \\
>50 \% \text {, complete occlusion, } \\
\text { dye filling defect }\end{array}$ \\
\hline $\begin{array}{l}\text { Bony lesions (bony } \\
\text { spur, osteophyte) }\end{array}$ & $\begin{array}{c}\text { Not seen or } \\
\text { distinguishable }\end{array}$ & $\begin{array}{l}\text { Barely visible or } \\
\text { distinguishable }\end{array}$ & Adequately seen & Clear demonstration \\
\hline $\begin{array}{l}\text { Intervertebral disc } \\
\text { abnormality }\end{array}$ & $\begin{array}{c}\text { Not seen or } \\
\text { distinguishable }\end{array}$ & $\begin{array}{l}\text { Barely visible or } \\
\text { distinguishable }\end{array}$ & Adequately seen & Clear demonstration \\
\hline $\begin{array}{l}\text { Nerve root } \\
\text { compression }\end{array}$ & $\begin{array}{c}\text { Not seen or } \\
\text { distinguishable }\end{array}$ & $\begin{array}{l}\text { Barely visible or } \\
\text { distinguishable }\end{array}$ & Adequately seen & Clear demonstration \\
\hline
\end{tabular}

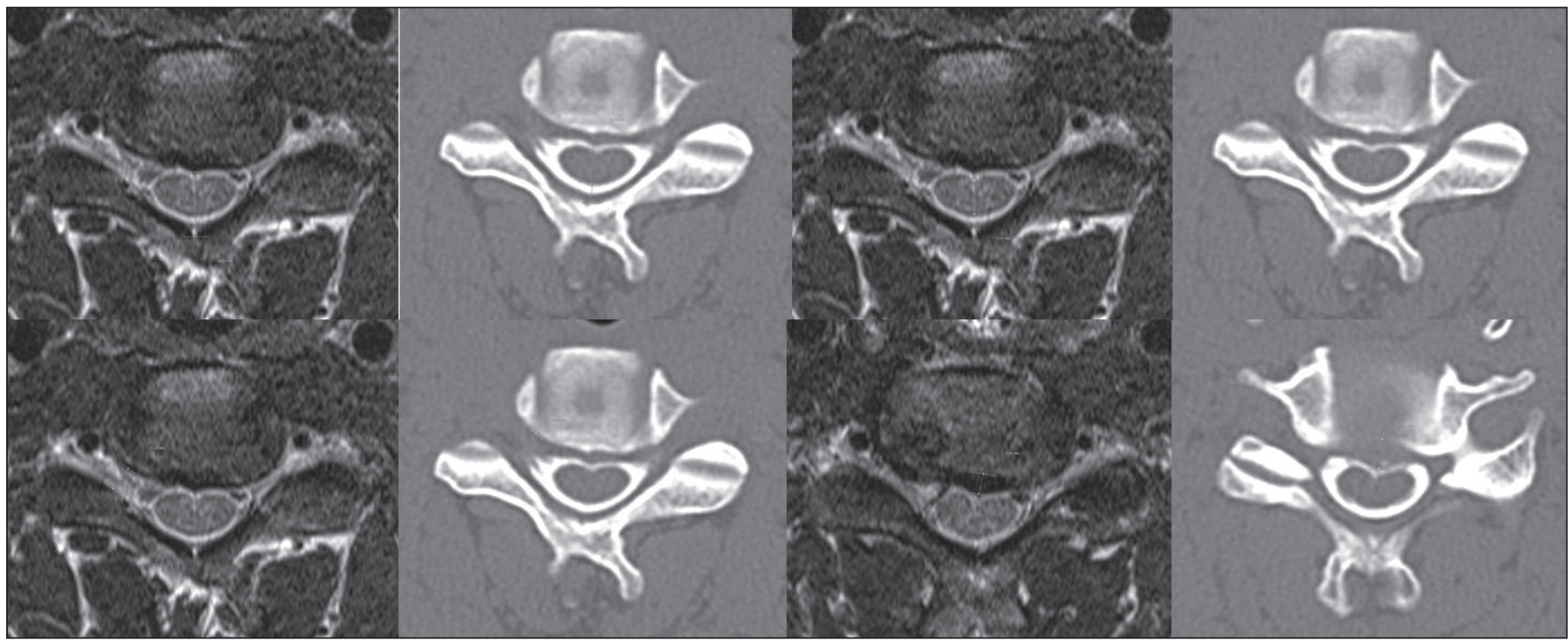

Figure 1: Spinal canal, neural foraminal, spinal cord and disc protrusion diameters were measured in axial plane of MRI and PMCT on digital radiographic image displayed by PACS terminal by observers. 
of $17.9 \%$, consisting of $16.8 \%$ in non-stenosed and $20.8 \%$ in stenosed segments (Figure 2B). No significant differences of cervical cord diameter measured in 3P-MRI compared to PMCT were observed. Furthermore, no significant differences could be found for the size of the disc protrusion between 3P-MRI and PMCT.

For the additional 2 questions ("what is the level of pathology" and "which segments require operation"), both questions yielded significantly higher results in 3P-MRI compared to PMCT (Table IV). Observers answered that out of 680 segments, 408 segments (64.1\%) were pathologic and 376 segments $(55.2 \%)$ required operation in 3P-MRI. However, they answered that 394 segments $(57.8 \%)$ were pathologic and 324 segments $(47.7 \%)$ required operation in PMCT. The discrepancies for the two questions were $6.3 \%$ and $7.5 \%$, respectively.

\section{DISCUSSION}

Changes of cervical canal volume according to flexible neck motion are important factors in CSM pathophysiology $(10,17,29)$. Many studies have demonstrated physiologic changes of cord diameter and length in different neck positions $(6,12,19,33)$. Recently, various authors have published kinematic MRI studies with positive results and its emphasis seems unquestionable especially in cervical spine with high flexibility $(2,9,10,13,17)$. However, to date, preoperative CSM evaluation is generally based on neutral position MRI in the majority of spine centers because kinematic MRI requires time and expenses for additional scanning in three different neck positions; neural, flexion and extension. Moreover, MR examination should be performed at the maximum active neck flexion and extension for accurate diagnosis which could be of neurologic risk to CSM patients. In our institute, we developed a routine protocol to perform 3P-MRI in all newly diagnosed CSM patients; with the help of custom-built positioning sponge under the head and shoulders, patients were able to lodge in the maximum comfortable position and routine medical doctor attendance was mandatory for close observation in case of neurologic worsening.

It is well known that even though MRI is believed to be the gold standard in the visualization of soft tissue pathologies of spinal and foraminal stenosis, its spatial relation to calcified

Table II: Result of Inter-Observer and Intra-Observer Agreement Between 3P-MRI and PMCT

\begin{tabular}{lcccc}
\hline \multirow{2}{*}{ Parameters } & \multicolumn{2}{c}{ Intra-observer Agreement } & \multicolumn{2}{c}{ Inter-observer Agreement } \\
\cline { 2 - 5 } & 3P-MRI & PMCT & 3P-MRI & 0.63 \\
\hline Spinal canal stenosis & 0.72 & 0.75 & 0.45 & 0.62 \\
\hline Foraminal stenosis & 0.54 & 0.68 & 0.38 & 0.64 \\
\hline Bony lesions & 0.52 & 0.66 & 0.66 & 0.48 \\
\hline Disc abnormality & 0.71 & 0.42 & 0.56 & 0.36 \\
\hline
\end{tabular}

3P-MRI: 3-position MRI(neutral, flexion, extension), PMCT: post-myelographic CT.

Table III: Results of Mean Values for Measured Diameters and Discrepancies Between 3P-MRI and PMCT

\begin{tabular}{|c|c|c|c|c|c|}
\hline & $\begin{array}{c}\text { 3P-MRI diameter* } \\
\text { [mm] (土SD) }\end{array}$ & $\begin{array}{l}\text { PMCT diameter } \\
\text { [mm] ( } \pm \text { SD) }\end{array}$ & $\begin{array}{l}\text { Discrepancy } \\
(\mathrm{mm})\end{array}$ & Discrepancy (\%) & $\mathbf{p}$ \\
\hline Spinal canal & $7.49( \pm 1.66)$ & $8.74( \pm 2.17)$ & 1.25 & 14.3 & $<0.05$ \\
\hline Foraminal & $2.36( \pm 0.52)$ & $2.93( \pm 0.71)$ & 0.57 & 20.8 & $<0.05$ \\
\hline Spinal cord & $5.56( \pm 1.37)$ & $5.58( \pm 1.08)$ & 0.02 & 1.2 & $\mathrm{~N} / \mathrm{S}$ \\
\hline
\end{tabular}

*Mean value of 3 different positions measured in $3 P-M R I$.

Table IV: Results for Two Additional Questions; 1) "What is the Level of Pathology" and 2) "Which Segments Requires Operation" and Discrepancies Between 3P-MRI and PMCT

\begin{tabular}{llll}
\hline & 3P-MRI (\%) & PMCT (\%) & Discrepancy (\%) \\
\hline Level of pathology & $64.1(204 / 340)$ & $57.8(197 / 340)$ & 6.3 \\
\hline Segment requiring operation & $55.2(188 / 340)$ & $47.7(162 / 340)$ & 7.5 \\
\hline
\end{tabular}


lesions and bony structures are easily overestimated $(3,8,14)$. CT-imaging after intrathecal injection of contrast agents, so called PMCT, not only provides reliable information of bony structures (commonly accepted as the gold standard), but also comprehensive images of the dural sac and adjacent spinal nerve roots $(3,8,11,14,18)$. Due to these valuable merits, PMCT is still routinely performed in many spine centers, despite its invasiveness and possible complications such as low pressure symptoms, meningitis and nerve root injury $(18,21,31,32)$. To minimize the adverse events of intrathecal contrast injection, our institute has established a routine set-up system in the fluoroscopy room, CT suite and day care center. Thus, after initial intrathecal injection at the fluoroscopy room by experienced hands, PMCT could be obtained without delay and the patient was sent to the day care center to monitor adverse events within an hour at most. With these efforts, we were able to obtain complete imaging information for the treatment decision of all newly diagnosed CSM patients.
It is well-known that MRI provides excellent intervertebral disc images but identification of canal stenosis is limited in degenerative disease due to section thickness, partial volume and cerebrospinal fluid flow alteration $(4,5,22)$. However, in the present study, excellent intra-observer agreement was demonstrated in both spinal canal stenosis and disc abnormality, thus demonstrating that with the aid of kinematic evaluation, spinal canal stenosis could be reproduced more effectively. On the other hand, it is often difficult to obtain reliable information about foraminal stenosis and nerve root compression with cervical MRI as a result of small neural foramen and lack of epidural fat compared to the larger lumbar spine $(14,22,24)$. Our data proved similar results as PMCT demonstrated better intra- and inter-observer agreement for foraminal stenosis and bony lesions.

Even though foraminal stenosis and root compression eventually result from same foraminal narrowing pathology, their radiologic evaluation show opposite results in this study. Root compression showed more reliable data in 3P-MRI compared to PMCT, while bony lesion demonstrated
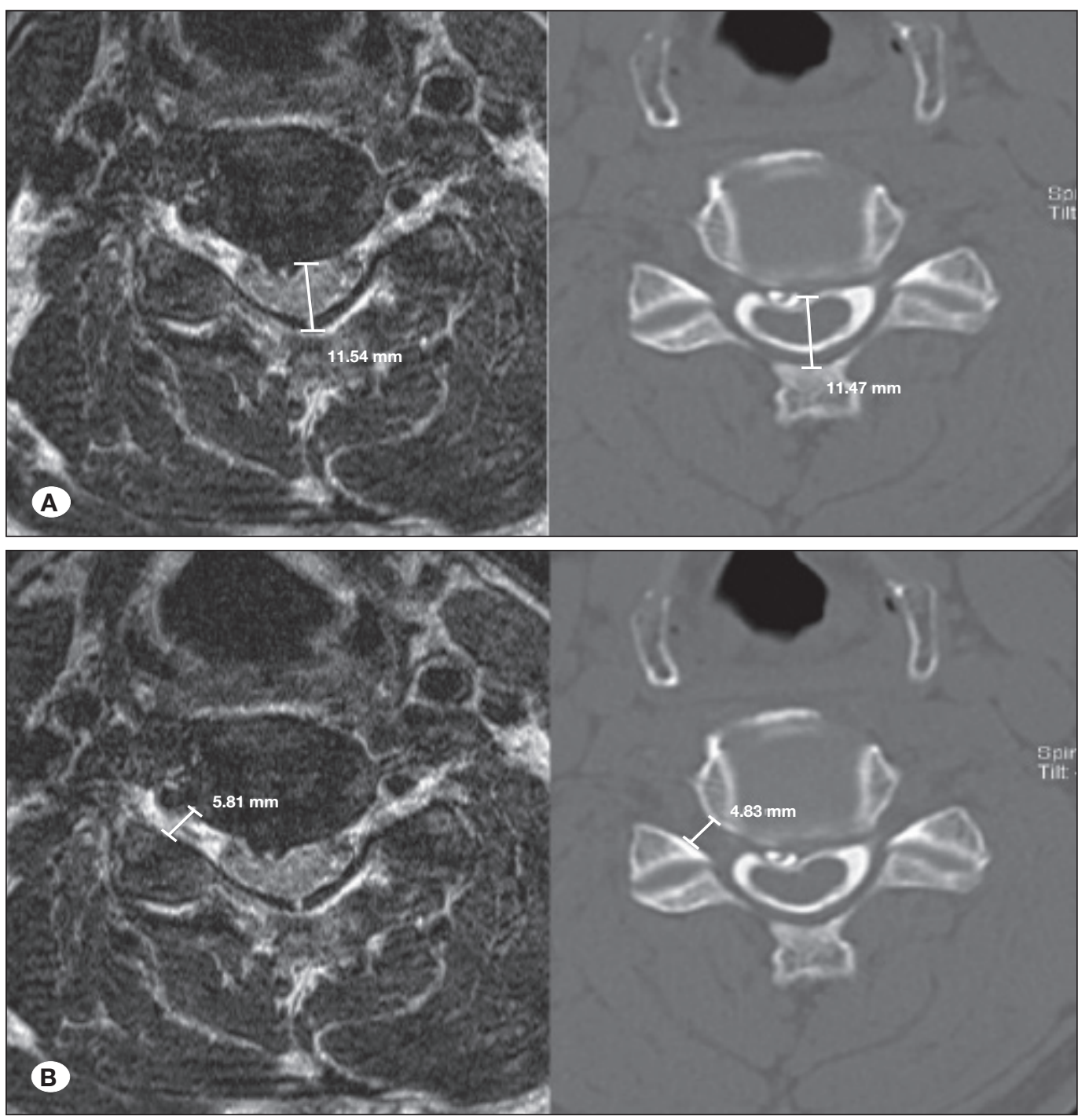

Figure 2: Example of spinal canal diameter (A) (left: 3P-MRI; right: $\mathrm{PMCT}$ ) and foraminal diameter (B) (left: 3P-MRI; right: $\mathrm{PMCT}$ ) discrepancies measured between 3P-MRI and PMCT. 
diametrical data (bony lesion in 3P-MRI and root compression in PMCT yielded poor inter-observer agreement especially). Our hypothesis is that this discrepancy results from the different characteristics of two diagnostic tools. Previous studies of 1.5-Tesla spinal MRI proved over-estimation of both spinal and foraminal stenosis which was more obvious in severe cases $(7,28,33)$. In our series, we used 3 -Tesla imaging in all 3P-MRI investigations, and recent studies have indicated that 3 -Tesla imaging is known to cause more pronounced susceptibility artifacts near bony lesions and pulsation artifacts caused by cerebrospinal fluid $(7,10,27)$. These effects also seem the most probable explanation for the discrepancy of spinal canal and foraminal diameters measured in the present study.

Our results have demonstrated that PMCT may be of great help in some ambiguous and difficult cases and there are limitations as a primary diagnostic modality in CSM. PMCT proved its usefulness as a better diagnostic tool in bony structural pathologic components such as foraminal stenosis and bony lesions. However, in soft neuronal components such as spinal stenosis, disc abnormality and nerve root compression, 3P-MRI demonstrated overt superior diagnostic accuracy. Moreover, with PMCT alone, cervical myelopathy and intramedullary lesions such as cord tumors and multiple sclerosis are easily overlooked $(1,14)$. However, surgical planning is an agonizing process and decision should be made with help of information from various diagnostic tools rather than with a single modality. Even with the "gold standard" of $\mathrm{MRI}$, obvious degenerative changes are often discovered in many asymptomatic patients $(7,13,16,18)$, and thus diagnosis of spinal pathology should always be accompanied by sufficient clinical examination and history taking.

As far as we are aware, this study is the first to compare 3P-MRI and PMCT in the diagnosis of CSM. We have retrospectively reviewed data of consecutive patients included in a controlled prospective registry at a single institute. However, this study has a few limitations. Firstly, it is a retrospective study with a small number of study subjects. A prospective cohort with a larger number of study subjects is needed for validation. Definition of multi-level CSM is not clarified and it may be different from surgeon to surgeon. Furthermore, diameters were measured by digital radiographic images displayed on the PACS terminal, not by automated software. Finally, acquired data was not differentiated by each cervical segment. Recent anatomical studies have shown that the C4 and C5 levels yield smaller diameters in normal population studies compared to the others $(7,9)$.

\section{- CONCLUSION}

In the present study, bony spinal canal and foraminal structures were shown to be overestimated with 3P-MRI in-comparison to PMCT. PMCT was still useful in the diagnosis of foraminal stenosis and bony lesions compared to 3P-MRI but showed limitation in disc abnormality and nerve root compression. Even though PMCT may provide valuable additional information in difficult or ambiguous cases, the universal standard of 3P-MRI proved higher reliability in detecting pathologic levels in CSM patients.

\section{REFERENCES}

1. Arlien-Soborg P, Kjaer L, Praestholm J: Myelography, CT, and MRI of the spinal canal in patients with myelopathy: $A$ prospective study. Acta Neurol Scand 87:95-102, 1993

2. Bakhsheshian J, Mehta VA, Liu JC: Current diagnosis and management of cervical spondylotic myelopathy. Global Spine J 7:572-586, 2017

3. Bischoff RJ, Rodriguez RP, Gupta K, Righi A, Dalton JE, Whitecloud TS: A comparison of computed tomographymyelography, magnetic resonance imaging, and myelography in the diagnosis of herniated nucleus pulposus and spinal stenosis. J Spinal Disord 6: 289-295, 1993

4. Czervionke LF, Daniels DL, Wehrli FW, Mark LP, Hendrix LE, Strandt JA, Williams AL, Haughton VM: Magnetic susceptibility artifacts in gradient-recalled echo MR imaging. AJNR Am J Neuroradiol 9:1149-1155, 1988

5. Dorenbeck U, Schreyer AG, Schlaier J, Held P, Feuerbach S, Seitz J: Degenerative diseases of the cervical spine: Comparison of a multiecho data image combination sequence with a magnetisation transfer saturation pulse and cervical myelography and CT. Neuroradiology 46:306-309, 2004

6. Endo K, Suzuki H, Nishimura H, Tanaka H, Shishido T, Yamamoto K: Kinematic analysis of the cervical cord and cervical canal by dynamic neck motion. Asian Spine J 8:747752, 2014

7. Grams AE, Gempt J, Forschler A: Comparison of spinal anatomy between 3-Tesla MRI and CT-myelography under healthy and pathological conditions. Surg Radiol Anat 32: 581-585, 2010

8. Jackson RP, Becker GJ, Jacobs RR, Montesano PX, Cooper BR, McManus GE: The neuroradiographic diagnosis of lumbar herniated nucleus pulposus: I. A comparison of computed tomography (CT), myelography, CT-myelography, discography, and CT-discography. Spine (Phila Pa 1976) 14: 1356-1361, 1989

9. Jiang X, Chen D, Lou Y, Li Z: Kinematic analysis of cervical spine canal diameter and its association with grade of degeneration. Eur Spine J 25: 2166-2172, 2016

10. Kolcun JP, Chieng LO, Madhavan K, Wang MY: The role of dynamic magnetic resonance imaging in cervical spondylotic myelopathy. Asian Spine J 11: 1008-1015, 2017

11. Kretzschmar K: Degenerative diseases of the spine. The role of myelography and myelo-CT. Eur J Radiol 27: 229-234, 1998

12. Kuwazawa Y, Pope MH, Bashir W, Takahashi K, Smith FW: The length of the cervical cord: Effects of postural changes in healthy volunteers using positional magnetic resonance imaging. Spine (Phila Pa 1976) 31: E579-583, 2006

13. Lao L, Daubs MD, Scott TP, Phan KH, Wang JC: Missed cervical disc bulges diagnosed with kinematic magnetic resonance imaging. Eur Spine J 23: 1725-1729, 2014

14. Larsson EM, Holtas S, Cronqvist S, Brandt L: Comparison of myelography, CT myelography and magnetic resonance imaging in cervical spondylosis and disk herniation. Pre- and postoperative findings. Acta Radiol 30: 233-239, 1989

15. McKay G, Torrie PA, Bertram W, Landham P, Morris S, Hutchinson J, Watura R, Harding I: Myelography in the assessment of degenerative lumbar scoliosis and its influence on surgical management. Korean J Spine 14: 133-138, 2017 
16. Merkle M, Maier G, Danz S, Kaminsky J, Tatagiba MS, Hebela $\mathrm{NM}$, Roser F: The value of dynamic radiographic myelography in addition to magnetic resonance imaging in detection lumbar spinal canal stenosis: A prospective study. Clin Neurol Neurosurg 143: 4-8, 2016

17. Miura J, Doita M, Miyata K, Marui T, Nishida K, Fujii M, Kurosaka M: Dynamic evaluation of the spinal cord in patients with cervical spondylotic myelopathy using a kinematic magnetic resonance imaging technique. J Spinal Disord Tech 22: 8-13, 2009

18. Morgalla M, Frantz S, Dezena RA, Pereira CU, Tatagiba $M$ : Diagnosis of lumbar spinal stenosis with functional myelography. J Neurol Surg A Cent Eur Neurosurg 79(4):316322, 2018

19. Muhle C, Wiskirchen J, Weinert D, Falliner A, Wesner F, Brinkmann G, Heller M: Biomechanical aspects of the subarachnoid space and cervical cord in healthy individuals examined with kinematic magnetic resonance imaging. Spine (Phila Pa 1976) 23: 556-567, 1998

20. Paholpak P, Nazareth A, Barkoh K, Lee LV, Lucas J, Buser Z, Wang JC: Space available for cord, motion, and disc degeneration at the adjacent segments level of degenerative cervical spondylolisthesis using kinematic MRI. J Clin Neurosci 45:89-99, 2017

21. Pomerantz SR: Myelography: Modern technique and indications. Handb Clin Neurol 135:193-208, 2016

22. Reul J, Gievers B, Weis J, Thron A: Assessment of the narrow cervical spinal canal: A prospective comparison of $\mathrm{MRI}$, myelography and CT-myelography. Neuroradiology 37:187191, 1995

23. Rhee J, Tetreault LA, Chapman JR, Wilson JR, Smith JS, Martin AR, Dettori JR, Fehlings MG: Nonoperative versus operative management for the treatment degenerative cervical myelopathy: An updated systematic review. Global Spine J 7: 35S-41S, 2017

24. Shafaie FF, Wippold FJ 2nd, Gado M, Pilgram TK, Riew KD: Comparison of computed tomography myelography and magnetic resonance imaging in the evaluation of cervical spondylotic myelopathy and radiculopathy. Spine (Phila $\mathrm{Pa}$ 1976) 24:1781-1785, 1999
25. Shiban $E$, von Lehe $M$, Simon $M$, Clusmann $H$, Heinrich P, Ringel F, Wilhelm K, Urbach $\mathrm{H}$, Meyer B, Stoffel M: Evaluation of degenerative disease of the lumbar spine: MR/ MR myelography versus conventional myelography/postmyelography CT. Acta Neurochir (Wien) 158: 1571-1578, 2016

26. Song KJ, Choi BW, Kim GH, Kim JR: Clinical usefulness of CTmyelogram comparing with the $\mathrm{MRI}$ in degenerative cervical spinal disorders: Is CTM still useful for primary diagnostic tool? J Spinal Disord Tech 22: 353-357, 2009

27. Takahashi S, Lord EL, Hayashi T, Cohen JR, Lao L, Yao Q, Suzuki A, Nakamura H, Wang JC: Radiologic factors associated with the dynamic change of dural sac diameter in lumbar spine: A kinematic MRI study. Clin Spine Surg 30: E827-E832, 2017

28. Tench CR, Morgan PS, Constantinescu CS: Measurement of cervical spinal cord cross-sectional area by MRI using edge detection and partial volume correction. J Magn Reson Imaging 21:197-203, 2005

29. Tetreault LA, Skelly AC, Dettori JR, Wilson JR, Martin AR, Fehlings MG: Guidelines for the management of degenerative cervical myelopathy and acute spinal cord injury: Development process and methodology. Global Spine J 7:8S-20S, 2017

30. Thornbury JR, Fryback DG, Turski PA, Javid MJ, McDonald JV, Beinlich BR, Gentry LR, Sackett JF, Dasbach EJ, Martin PA: Disk-caused nerve compression in patients with acute low-back pain: Diagnosis with MR, CT myelography, and plain CT. Radiology 186: 731-738, 1993

31. Waly FJ, Abduljabbar FH, Fortin M, Nooh A, Weber M: Preoperative computed tomography myelography parameters as predictors of outcome in patients with degenerative cervical myelopathy: Results of a systematic review. Global Spine J 7: 521-528, 2017

32. Westermaier T, Doerr C, Stetter C, Linsenmann T, Koehler S, Eriskat J, Solymosi L, Ernestus RI: Influence of myelography and postmyelographic ct on therapeutic decisions in degenerative diseases of the cervical spine. Clin Spine Surg 30: E656-E661, 2017

33. Yanase M, Matsuyama $Y$, Hirose K, Takagi H, Yamada M, Iwata $\mathrm{H}$, Ishiguro $\mathrm{N}$ : Measurement of the cervical spinal cord volume on MRI. J Spinal Disord Tech 19:125-129, 2006 